\title{
Calcium phosphate glasses: Silanation process and effect on the bioactivity behavior of Glass-PMMA composites
}

\author{
Lizette Morejón Alonso, ${ }^{1}$ José Ángel Delgado García-Menocal, ${ }^{2}$ Mariona Tarragó Aymerich, ${ }^{3}$ \\ Julio Ándrés Álvarez Guichard, ${ }^{4}$ Maite García-Vallés, ${ }^{3}$ Salvador Martínez Manent, ${ }^{3}$ \\ Maria-Pau Ginebra ${ }^{5}$ \\ ${ }^{1}$ Macromolecular Department, Center of Biomaterials, University of Havana, Havana, Cuba \\ ${ }^{2}$ Ceramics and Composites Department, Center of Biomaterials, University of Havana, Havana, Cuba \\ ${ }^{3}$ Crystallography, Mineralogy and Mineral Deposits Department, Geology Faculty, University of Barcelona, Barcelona, Spain \\ ${ }^{4}$ General Chemistry Department, Chemistry Faculty, University of Havana, Havana, Cuba \\ ${ }^{5}$ Department of Material Science and Metallurgical Engineering, Technical University of Catalonia, Barcelona, Spain
}

Received 26 February 2013; revised 16 May 2013; accepted 6 June 2013

Published online in Wiley Online Library (wileyonlinelibrary.com). DOI: 10.1002/jbmb.32996

\begin{abstract}
This article presents the results of a study of the efficiency of silanation process of calcium phosphate glasses particles and its effect on the bioactivity behavior of glasspoly(methyl methacrylate) (PMMA) composites. Two different calcium phosphate glasses: $44.5 \mathrm{CaO}-44.5 \mathrm{P}_{2} \mathrm{O}_{5}-11 \mathrm{Na}_{2} \mathrm{O}$ (BV11) and $44.5 \mathrm{CaO}-44.5 \mathrm{P}_{2} \mathrm{O}_{5}-6 \mathrm{Na}_{2} \mathrm{O}-5 \mathrm{TiO}_{2}$ (G5) were synthesized and treated with silane coupling agent. The glasses obtained were characterized by Microprobe and BET while the efficiency of silanation process was determined using Fourier Transform Infrared Spectroscopy (FTIR), X-ray Photoelectron Spectroscopy (XPS) and Thermal Analysis (DTA and TG) techniques. The content of coupling agent chemically tightly bond to the silanated glasses ascended to $1.69 \pm 0.02 \mathrm{wt} \%$
\end{abstract}

for BV11sil glass and $0.93 \pm 0.01$ wt $\%$ for G5sil glass. The in vitro bioactivity test carried out in Simulated Body Fluid (SBF) revealed certain bioactive performance with the use of both silanated glasses in a $30 \%$ (by weight) as filler of the PMMA composites because of a superficial deposition of an apatite-like layer with low content of $\mathrm{CO}_{3}{ }^{2-}$ and $\mathrm{HPO}_{4}{ }^{2-}$ in its structure after soaking for 30 days occurred. (c) 2013 Wiley Periodicals, Inc. J Biomed Mater Res Part B: Appl Biomater 00B: 000-000, 2013.

Key Words: calcium phosphate glasses, poly(methyl methacrylate) (PMMA), silane, bioactivity, bone cements

How to cite this article: Morejón L, Delgado JA, Tarragó M, Álvarez JA, García-Vallés M, Martínez S, Ginebra MP. 2013. Calcium phosphate glasses: Silanation process and effect on the bioactivity behavior of Glass-PMMA composites. J Biomed Mater Res Part B 2013: 00B: 000-000.

\section{INTRODUCTION}

Bioactive glasses are useful materials in the process of bone tissues regeneration as a consequence of their ability of binding the living bone when they are implanted in hard tissues. ${ }^{1}$ In the 60 's-70's were founded by Hench that the silica-rich glasses create a direct bond to living bone through a hydroxycarbonateapatite (HCA) layer formed onto their surfaces. ${ }^{2}$ Since that, a trademark Bioglass® (45 wt $\% \mathrm{SiO}_{2}, 24.5$ wt $\% \mathrm{CaO}, 24.5$ wt $\% \mathrm{Na}_{2} \mathrm{O}, 6$ wt $\% \mathrm{P}_{2} \mathrm{O}_{5}$ ) has been widely used in medical research with excellent clinical results, ${ }^{2-4}$ and subsequently, several devices based on silicarich glasses have been used in surgical bone repair, such as Ceravital ${ }^{\circledR}, \quad$ Apatite/Wollastonite bioactive glass-ceramic (AW-GC) and Bioverit $\AA^{2,5}$

The process of in vivo osseointegration of silica-rich glasses is well recognized. This bioactive performance can be reproduced using in vitro techniques through soaking the material in Simulated Body Fluid (SBF) in which a new calcium phosphate phase (calcium-deficient apatite crystals similar to those formed in the living body, named as "bonelike apatite") is created on their surfaces. This process is known as biomimetic formation of apatite of bioactive materials. ${ }^{6}$ However, due to the insolubility of the silica-rich glasses they are only used as a component of long-term devices.

In contrast, calcium phosphate glasses are currently studied because they can be prepared with a chemical composition analogous to the natural bone, their solubility can be tailored to specific applications ${ }^{7,8}$ and different biocompatibility studies have demonstrated that these glasses do not produce adverse cell reactions on osteoblasts or fibroblasts. $^{9-11}$ In addition, some reports reveal that calcium phosphate glasses can support the attachment, growth, and differentiation of human osteoblasts and fibroblasts. ${ }^{10}$ For these reasons, calcium phosphate glasses have a great potential in the development of degradable devices, as well as, in the building of temporary scaffolds intended to support the regeneration of hard tissues. ${ }^{12,13}$ In order to 
control the solubility of calcium phosphate glasses in humid environments, ions such as: $\mathrm{Fe}^{3+}, \mathrm{Al}^{3+}, \mathrm{Zn}^{2+}$, and $\mathrm{Ti}^{4+}$ have been used in novel glass formulations. ${ }^{14,15}$

One of the most usual applications of bioactive materials is as a filler of composites in order to increase the bioactive behavior of different polymers. ${ }^{16-18}$ In that case it is common the use of silane coupling agents to reinforce adhesion between the inorganic filler and the matrix polymer. ${ }^{19,20}$ Parameters such as solvent type, catalyst, and drying process determine the efficiency of silane adhesion. ${ }^{19}$

Returning to bioactive silica-rich glasses, the essential role of the silicate ions in the mechanism to produce the interfacial reactions that leads to the calcium phosphate deposition (bioactive performance) is well recognized from in vitro and in vivo studies. It is established that the mechanism of hydroxyapatite (HA) formation involves dissolution of $\mathrm{Ca}^{2+}$ ions from the surface of bioactive materials, which increase the saturation in the surrounding fluid, with respect to HA components. The simultaneous dissolution of silicates results in formation of silanol groups (Si-OH) on the material's surface and promotes the nucleation sites for HA formation. ${ }^{2}$

In the case of calcium phosphate glasses, several studies are related to their dissolution behaviors in living body or humid environment; ${ }^{21}$ however, their bioactive performance is still under discussion. ${ }^{14,22,23}$ Considering both the fact that $\mathrm{Si}$ ions have an specific function in order to promote the bioactive behavior of silica-rich glasses and the convenient use of glasses as a component of bioactive composites, this work analyzes the efficiency of the silanation process of two different calcium phosphate glasses with different solubilities: $44.5 \mathrm{CaO}-44.5 \mathrm{P}_{2} \mathrm{O}_{5}-11 \mathrm{NaO}$ (BV11 glass) and 44.5 CaO-44.5 $\mathrm{P}_{2} \mathrm{O}_{5}-6 \mathrm{NaO}-5 \mathrm{TiO}_{2}$ (G5 glass) using mainly infrared spectroscopy (FTIR), X-ray photoelectron spectroscopy (XPS) and thermal analysis (TG and DTA). A preliminary study of the in vitro bioactive behavior of silanated calcium phosphate glass-poly (methyl methacrylate) composites by immersion in SBF is also carried out.

\section{MATERIALS AND METHODS}

\section{Glass preparation}

Two glass compositions were prepared using $\mathrm{CaO}, \mathrm{Na}_{2} \mathrm{CO}_{3}$, $\mathrm{NH}_{4} \mathrm{H}_{2} \mathrm{PO}_{4}$, and $\mathrm{TiO}_{2}$ (Panreac) as raw materials to obtain the following nominal composition (mol \%): 44.5CaO$44.5 \mathrm{P}_{2} \mathrm{O}_{5}-11 \mathrm{NaO}$ (BV11) and 44.5CaO-44.5 $\mathrm{P}_{2} \mathrm{O}_{5}-6 \mathrm{NaO}-5 \mathrm{TiO}_{2}$ (G5). The precursors were weighed, homogenously mixed and melted in a Pt $/ 10 \% \mathrm{Rh}$ crucible at $1250-1350^{\circ} \mathrm{C}$ for $8 \mathrm{~h}$ at a rate of $2^{\circ} \mathrm{C} \min ^{-1}$. The mixture was cast in a preheated metallic mold at $350-530^{\circ} \mathrm{C}$ depending on the glass transition temperature $\left(T_{g}\right)$ of each glass. Finally, the glasses were annealed at their $T_{\mathrm{g}}$ and cooled slowly to eliminate any residual stress.

Silanation procedure. The glasses were pulverized $(\leq 90 \mu \mathrm{m})$ using agate planetary mill and were treated with $\gamma$-methacryloxypropyltrimethoxysilane ( $\gamma$-MPS) (Aldrich Chemical Co., Milwaukee, WI) in acetone. The glass particles were dried at $100{ }^{\circ} \mathrm{C}$ for $2 \mathrm{~h}$ at atmospheric pressure before the reaction. For the silanation process $5 \mathrm{~g}$ of glass particles were agitated for $2 \mathrm{~h}$ in acetone with $0.3 \mathrm{vol} \%$ of water and 4 vol $\%$ of $\gamma$-MPS (of total solvent volume), sonicated for $20 \mathrm{~min}$ and additionally agitated for $2 \mathrm{~h}$. The silanated particles were separated using a centrifuge, washed tree times with pure acetone, dried at room temperature overnight and then in the oven at $100^{\circ} \mathrm{C}$ for $2 \mathrm{~h}$. The silanated samples were named BV11sil and G5sil.

\section{Glass powder characterization}

Chemical composition and particle size distributions. The chemical composition of the synthesized glasses was measured by electron microprobe analyses. The samples were embedded in epoxy resin and transversal cross sections were cut with low-deformation diamond saw. After polishing, they were analyzed in the electron microprobe (EM) and SEM/EDS (model Camebacx SX-50, CAMECA, Coubevoic, France) to determine the chemical composition of the glasses. Ten profiles crossing each specimen were measured to picture the homogeneity of the glass. The particle size distribution to the silanated glasses was determined using a Beckman Coulter LS 13320 Particle Size Analyzer. 10 mg of each sample were dispersed in ethanol and $3 \mathrm{~min}$ of ultrasound were applied previously to the analysis.

Infrared spectroscopy (FTIR). The silanated powders were characterized by infrared spectroscopy (Perkin Elmer Spectrum One). About $10 \mathrm{mg}$ of each sample was blended with $\mathrm{KBr}$ for IR spectroscopy (Sigma-Aldrich) and then pressed into translucent pellets for the measured. Spectra between $4000-400 \mathrm{~cm}^{-1}$ range were obtained from co-addition of 100 scans.

X-ray photoelectron spectroscopy (XPS) analysis. Unsilanated and silanated glass powder samples were characterized by X-ray photoelectron spectroscopy (XPS). The experiments were performed in a PHI 5500 Multitechnique System (from Physical Electronics, MN) with a monochromatic X-ray source (Aluminium $\mathrm{K} \alpha$ line of $1486.6 \mathrm{eV}$ energy and 350 $W$ ), placed perpendicular to the analyzer axis and calibrated using the 3d5/2 line of $\mathrm{Ag}$ with a full width at half maximum (FWHM) of $0.8 \mathrm{eV}$. The analyzed area was a circle of $0.8 \mathrm{~mm}$ diameter, and the selected resolution for the spectra was $187.5 \mathrm{eV}$ of Pass Energy and $0.8 \mathrm{eV} / \mathrm{step}$ for the general spectra and $23.5 \mathrm{eV}$ of Pass Energy and $0.1 \mathrm{eV} / \mathrm{step}$ for the spectra of the different elements in the depth profile spectra. In-depth measurements for composition depth profiles were obtained by sputtering the surface with an $\mathrm{Ar}+$ ion source (4 keV energy). A low energy electron gun (less than $10 \mathrm{eV}$ ) was used in order to discharge the surface when necessary. All measurements were made in a ultra high vacuum (UHV) chamber at pressure between $5 \times 10^{-9}$ and $2 \times 10^{-8}$ torr.

Surface area (BET). The textural characterization was conducted by the application of gravimetric nitrogen Brunauer-Emmett-Teller (BET) surface analysis technique, using a Micromeritics ASAP 2020 Micropore Analyser 
(Micromeritics, Norcross, GA). About 8,0 g of each sample were used for the testing and they were outgassed prior to the determination.

Thermal analysis (DTA and TGA). Differential thermal analysis (DTA; TA Instruments NETZSCH STA 409, Exton, PA) was conducted to identify the glass transition $\left(T_{\mathrm{g}}\right)$, crystallization $\left(T_{\mathrm{c}}\right)$ and melting $\left(T_{\mathrm{m}}\right)$ temperatures of the studied glasses. Analyses were carried out on powdered glass samples $(50 \mathrm{mg})$ in a Pt crucible from 25 to $800^{\circ} \mathrm{C}$ at a heating rate of $10^{\circ} \mathrm{C} / \mathrm{min}$ under air atmosphere. A crucible with alumina $\left(\mathrm{Al}_{2} \mathrm{O}_{3}\right)$ was used as a reference. Also, the silane transformations under heating were determined. The thermogravimetric analysis (TGA) was used to quantify the total weight loss of the silane coupling.

\section{Preparation of Glass-PMMA composites}

Composites based on poly(methyl methacrylate) bone cements and silanated glasses particles were prepared. It was used as a Solid Part: 60 wt \% of PMMA beads (Bonar Polymer) containing $2.6 \mathrm{wt} \%$ of benzoyl peroxide, 10.0 wt $\%$ of barium sulphate $\left(\mathrm{BaSO}_{4}\right)$ (J.T. Baker) as radiopaque agent, and 30 wt \% of silanated glass particles. For the Liquid Part 97.3 vol \% of methyl methacrylate (MMA) (Merck), 2.7 vol \% of $N, N$-dimethyl-p-toluidine (DMPT) (Merck) as coinitiator and $80.0 \mathrm{ppm}$ of hydroquinone (HQ) (Aldrich) as stabilizer were mixed. A 2/1 solid/liquid ratio was used for all formulations.

\section{Bioactivity tests of glass-PMMA composites}

The bioactivity of the formulations was studied by soaking the composite samples in $\mathrm{SBF}^{6}$ Discs of $10 \mathrm{~mm}$ diameter and $1 \mathrm{~mm}$ thickness of the composites were made mixing the liquid and the solid components at room temperature using Teflon molds. The specimens were exposed to $20 \mathrm{~mL}$ of fresh solutions of SBF prepared using the Kokubo's proto$\mathrm{col}^{6}$ under static conditions at $37 \pm 1^{\circ} \mathrm{C}$ during 30 days and the solution was not replaced during the assay. After exposure, the samples were washed off with ethanol, dried at room temperature for $24 \mathrm{~h}$ and stored in a desiccator until used. The morphology of the coatings formed on the surface of the composites were studied by directly observation of surface's discs using analytical Environmental Scanning Electron Microscopy on ESEM Quanta 200 FEI, XTE 325/ D8395 by Energy Dispersive X-ray Spectroscopy (EDS). The composition of the coating pulled out by hand was determined by Fourier-Transformed Infrared (FTIR) spectroscopy on a Bomem MB120 (Quebec, Canada).

\section{RESULTS}

\section{Glass powder characterization}

The chemical compositions measured by microprobe of both calcium phosphate glasses synthesized in this work are reported in Table I. Both materials were in good agreement with the mole percentage of the reactants. BET surface area for the glass particles is also reported in Table I. The G5 glass resulted with a slightly higher surface area when compared with the BV11 glass. The infrared patterns of calcium
TABLE I. Glass Compositions Measured by Microprobe Analysis and BET Area

\begin{tabular}{lccccr}
\hline & \multicolumn{4}{c}{ Composition (mol \%) $\pm \mathrm{SD}$} & \multicolumn{2}{c}{ BET Area } \\
\cline { 2 - 4 } Sample & $\mathrm{P}_{2} \mathrm{O}_{5}$ & $\mathrm{CaO}$ & $\mathrm{Na}_{2} \mathrm{O}$ & $\mathrm{TiO}_{2}$ & $\left(\mathrm{~m}^{2} / \mathrm{g}\right) \pm \mathrm{SD}$ \\
\hline $\mathrm{BV} 11$ & $46.2 \pm 0.7$ & $48.9 \pm 0.3$ & $9.9 \pm 0.3$ & - & $0.190 \pm 0.006$ \\
$\mathrm{G} 5$ & $46.7 \pm 0.4$ & $45.4 \pm 0.4$ & $6.5 \pm 0.2$ & $5.5 \pm 0.1$ & $0.230 \pm 0.007$ \\
\hline
\end{tabular}

phosphate glasses are shown in Figure 1(a). The typical bands of the $\mathrm{PO}_{4}{ }^{3-}$ groups appear at $1400-800 \mathrm{~cm}^{-1}$, while the FTIR spectra of the silanated glasses exhibit in addition the characteristic absorption bands of $\gamma$-MPS. The vibrations at 2945 and $2841 \mathrm{~cm}^{-1}$ correspond with the $v^{\text {as }}\left(-\mathrm{CH}_{3}\right)$ and $v^{\text {as }}\left(-\mathrm{CH}_{2}\right)$ respectively of the carbonated chain of the $\gamma$ MPS. The band at $\lambda=1718 \mathrm{~cm}^{-1}$ is associated to the carbonyl group $(\mathrm{C}=0)$ stretching vibration. The size particle distributions resulted very similar for both silanated glasses as can be seen in Figure 1(b) with an average particle size
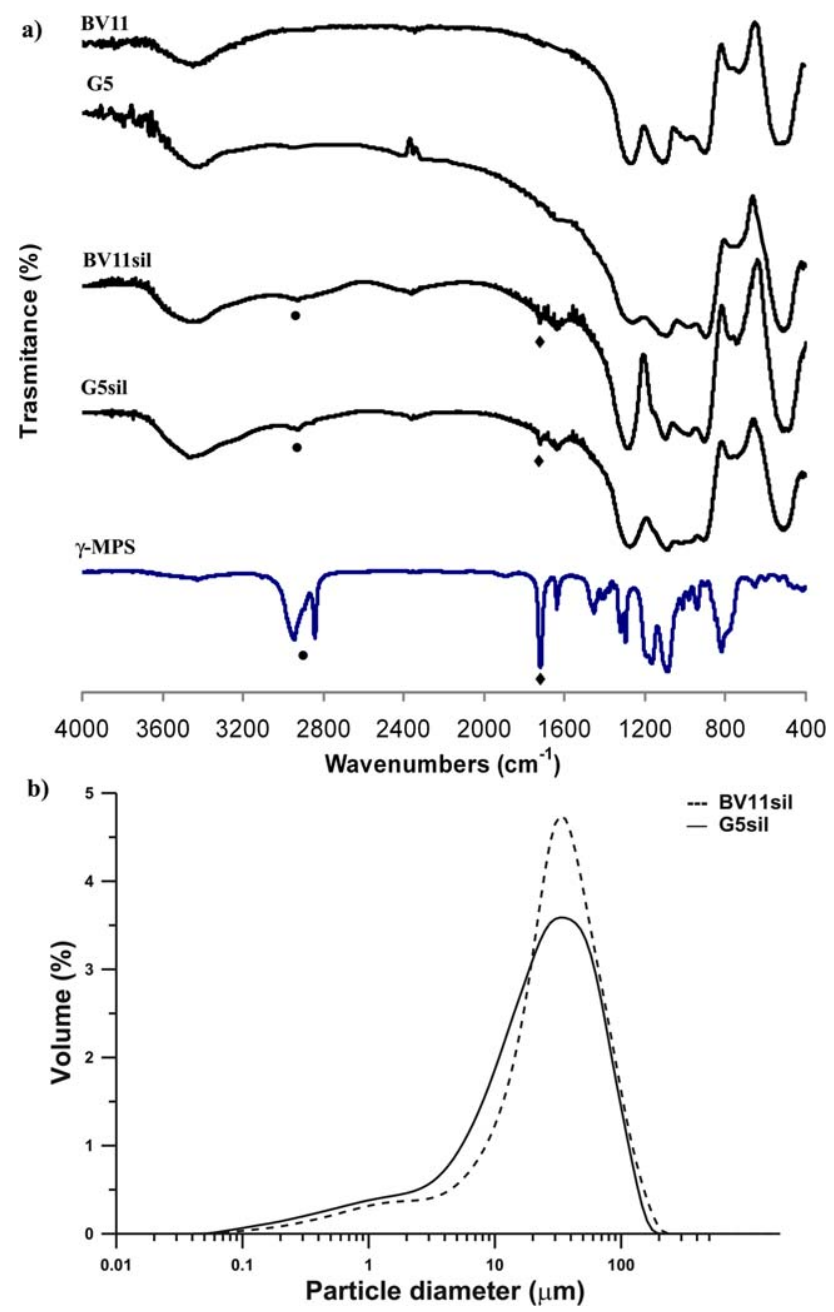

FIGURE 1. (a) FTIR spectra of silanated glass particles and silane coupling agent. $(\bullet) \lambda=2945 \mathrm{~cm}^{-1} v^{\text {as }}\left(-\mathrm{CH}_{3}\right)$ and $\lambda=2841 \mathrm{~cm}^{-1} v$ as $\left(-\mathrm{CH}_{2}\right)$, $(\diamond)$ carbonyl stretching vibration $\mathrm{v}(\mathrm{C}=\mathrm{O})$ corresponding to silane coupling agent; (b) particle size distributions for BV11sil and G5sil glasses. [Color figure can be viewed in the online issue, which is available at wileyonlinelibrary.com.] 

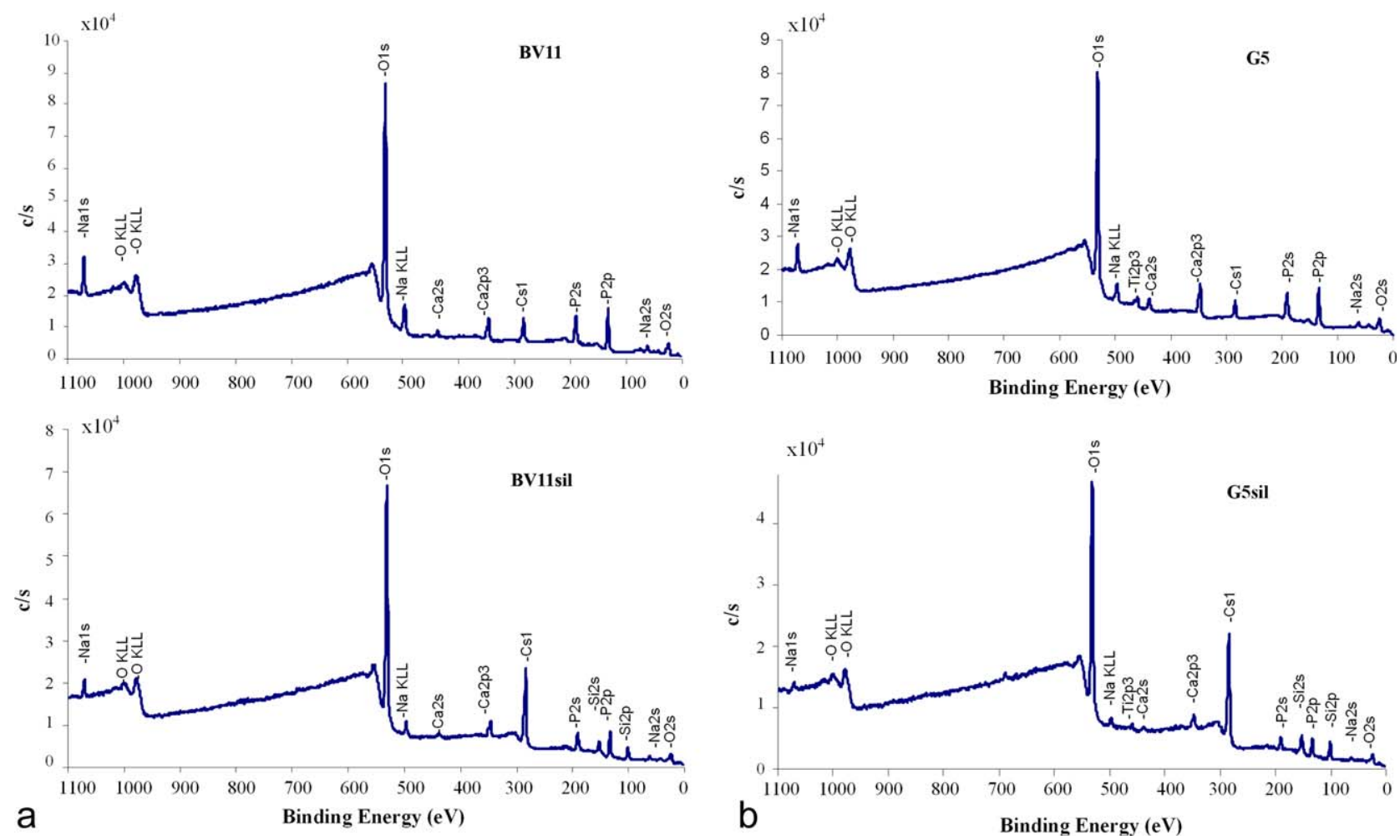

FIGURE 2. (a) XPS spectra of BV11 glass before and after silanation process. (b) XPS spectra of G5 glass before and after silanation process. [Color figure can be viewed in the online issue, which is available at wileyonlinelibrary.com.]

of $39,68 \mu \mathrm{m}\left(d_{10}: 4,66 \mu \mathrm{m} ; d_{50}: 31,85 \mu \mathrm{m}\right.$ and $d_{90}: 84.25$ $\mu \mathrm{m})$ for BV11sil and $34,17 \mu \mathrm{m}\left(d_{10}: 2,76 \mu \mathrm{m} ; d_{50}: 25,50 \mu \mathrm{m}\right.$ and $\left.d_{90}: 77,90 \mu \mathrm{m}\right)$ for G5sil.

XPS wide scan (Figure 2) identified oxygen, calcium, phosphorous, and sodium as the major constituents of BV11 glass [Figure 2(a)] as well as oxygen, calcium, phosphorous, sodium, and titanium as the major elements of G5 glass [Figure 2(b)], as expected. The atomic concentrations for both untreated and treated with $\gamma$-MPS coupling agent samples are summarized in Table II. Silane addition caused a decrease of Ca (2p) from $2.82 \%$ and $4.58 \%$ to $1.43 \%$ and $1.17 \%$ for BV11 and G5 unsilanated samples in comparison with silanated samples. In addition, $\mathrm{P}(2 \mathrm{p})$ concentration decreases from $15.86 \%$ (BV11) and $16.89 \%$ (G5) to $7.41 \%$ (BV11sil) and 4.93\% (G5sil). Si (2s) and Si (2p) were detectable in both silanated samples and $\mathrm{C}(1 \mathrm{~s})$ and $\mathrm{O}(1 \mathrm{~s})$ increase its atomic concentrations because of the carbonated chain belonging to the coupling agent.

TABLE II. XPS Analysis Atomic Concentration of Unsilanated Glasses and Silanated Glasses

\begin{tabular}{lcccccccc}
\hline & \multicolumn{7}{c}{ Concentration (\%) } \\
\cline { 2 - 9 } Sample & C1s & O1s & Na1s & Si2s & Si2p & P2p & Ca2p & Ti2p \\
\hline BV11 & 14.07 & 61.80 & 5.45 & - & - & 15.86 & 2.82 & - \\
G5 & 10.58 & 62.04 & 4.36 & - & - & 16.89 & 4.58 & 1.55 \\
BV11sil & 35.26 & 43.57 & 1.55 & 5.99 & 4.78 & 7.41 & 1.43 & - \\
G5sil & 42.28 & 37.92 & 0.61 & 7.13 & 5.96 & 4.93 & 1.17 & - \\
\hline
\end{tabular}

The results of the thermal analysis are exhibited in Figures 3-8. Two peaks of crystallization $\left(T_{\mathrm{c}}\right)$ and one peak associated to the melting process $\left(T_{\mathrm{m}}\right)$ are clearly observed in both samples without silane treatment (Figure 3). Table III summarizes glass transition temperature $\left(T_{\mathrm{g}}\right)$, crystallization temperature $\left(T_{\mathrm{c}}\right)$ and melting temperature $\left(T_{\mathrm{m}}\right)$ of the glasses. As expected, the G5 glass has higher glass transition and crystallization temperatures in comparison to BV11 glass due to the presence of $\mathrm{TiO}_{2}$ as an ionic modifier in the structure. Typical DTA curves of silane agent and silanated glasses are shown in Figure 4. Two exothermic peaks can be observed at $230^{\circ} \mathrm{C}$ and $395^{\circ} \mathrm{C}$ in the DTA curve of silane, which are associated with the decomposition in two steps of the $\gamma$-MPS coupling agent. Both silanated glasses revealed transformations at $200^{\circ} \mathrm{C}$, at $390^{\circ} \mathrm{C}$ for $\mathrm{BV} 11$ sil and at $400^{\circ} \mathrm{C}$ for G5sil indicating the presence of a certain amount of silane coupling agent retained after the reaction. A slight increase in both crystallization temperatures is observed for the G5sil sample apart from the increase of the melting temperature $\left(T_{\mathrm{m}}\right)$ which turned out higher than $800^{\circ} \mathrm{C}$ and is not detected. No significant changes in the temperatures of crystallization $\left(T_{\mathrm{c}}\right)$ or melting $\left(T_{\mathrm{m}}\right)$ was observed for BV11sil. It was not possible to clearly determine the glass transition temperatures $\left(T_{\mathrm{g}}\right)$ of silanated samples because of they were masked by the silane transformations, Table III.

Considering the TG analysis, Figure 5 shows the TG curve of the silane coupling agent while Figures 6 and 7 respectively exhibit the corresponding curves of the non 


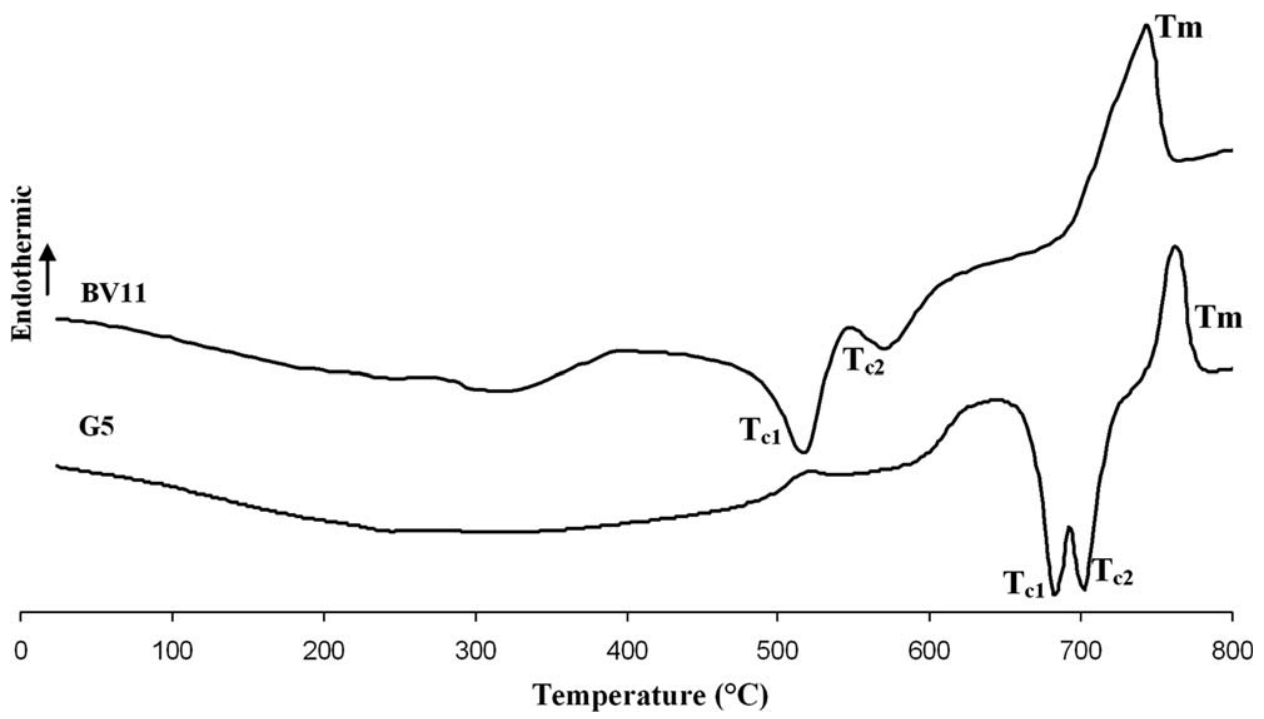

FIGURE 3. DTA curves of BV11 and G5 unsilanated.

silanated and silanated glasses. No significant weight loss was detected for the untreated samples up to $800^{\circ} \mathrm{C}$ while two-step weight losses were detected for the silanated glasses due to the tightly bound silane (chemical bond). The first one occurred between $280^{\circ}$ and $420^{\circ} \mathrm{C}$ and the second one occurred between $500^{\circ}$ and $600^{\circ} \mathrm{C}$. Figure 8 shows the differences between TG curves for G5 silanated glass washed exhaustively (three times) compared with one time washed G5sil sample. It can be seen that the slightly washed G5sil sample shows a three-step weight loss; the first weight change occurred between $100^{\circ}$ and $200^{\circ} \mathrm{C}$ and may be mainly attributed to the loss of loosely adsorbed silane. It can be observed in Figure 5 that the major decomposition of silane takes place between $100^{\circ}$ and $200^{\circ} \mathrm{C}$, then a small weight loss occurs at high temperature $\left(\sim 350^{\circ} \mathrm{C}\right)$ and finally, around $9.2 \pm 0.1 \mathrm{wt} \%$ stays as residue. The loosely adsorbed silane can be washed away using acetone leaving only tightly adsorbed silane on the glass surface. The total amount of attached silane determined by TG analysis was $1.69 \pm 0.02 \mathrm{wt} \%$ for BV11sil glass and $0.93 \pm 0.01 \mathrm{wt} \%$

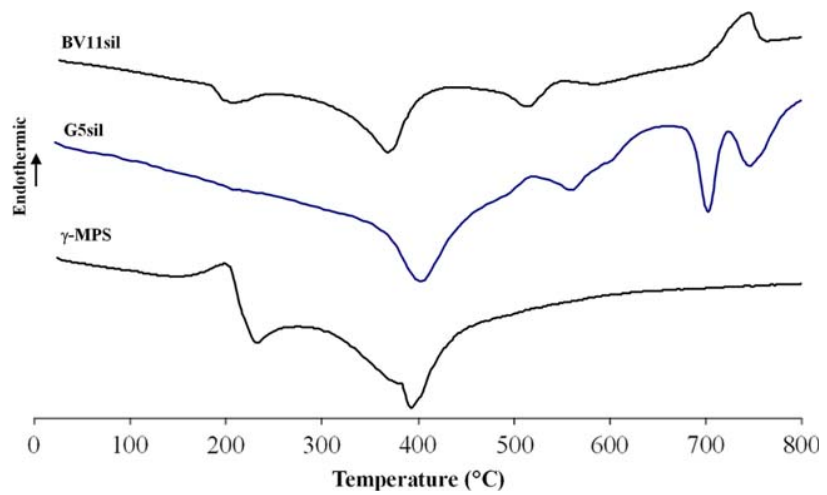

FIGURE 4. DTA curves of $\gamma$-MPS, BV11 silanated, and G5 silanated. [Color figure can be viewed in the online issue, which is available at wileyonlinelibrary.com.] for G5sil glass. In all TG curves were detected a slight increase in the mass for the first stage of the testing, this effect is called buoyancy effect and is related to the abrupt change in air density to start warming. The values reported for the weight loss take in consideration this fact.

\section{Bioactivity behavior of Glass-PMMA composites}

The influence of silanated glasses on the in vitro bioactivity performance of glass-PMMA composites was examined by soaking probes in SBF. SEM micrographs of the surfaces of PMMA cement samples without fillers did not reveal any morphological change after 30 days of soaking; only acrylic beads immerse in the acrylic matrix and inorganic component $\left(\mathrm{BaSO}_{4}\right)$ dispersed were detected. In contrast, SEM micrographs of acrylic bone cements with $30 \mathrm{wt} \%$ of silanated BV11 [Figure 9(a)] clearly showed superficial agglomerates of a $\mathrm{Ca} / \mathrm{P}$ rich layer covering the whole surface after 30 days of soaking. Samples of PMMA bone cement modified with 30 wt \% of G5sil [Figure 9(b)] show the incipient formation of a $\mathrm{Ca} / \mathrm{P}$ rich layer on some areas of the surface. The change in the surface morphology of the bone cement loaded with BV11sil is more significant in comparison to the

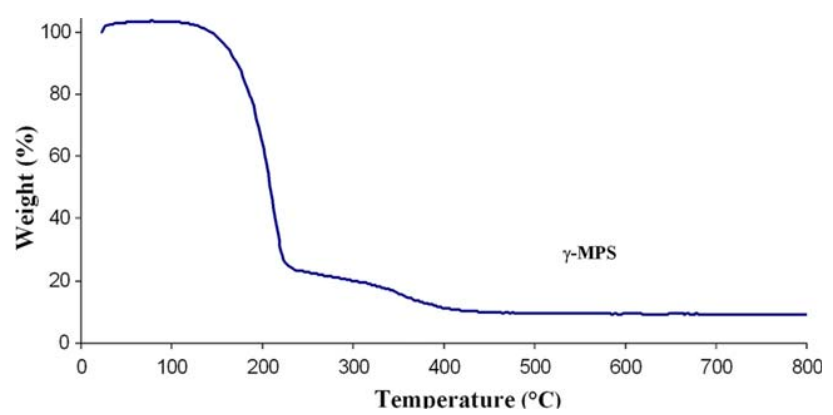

FIGURE 5. TGA curve of a drop of $\gamma$-MPS on alumina. [Color figure can be viewed in the online issue, which is available at wileyonlinelibrary.com.] 


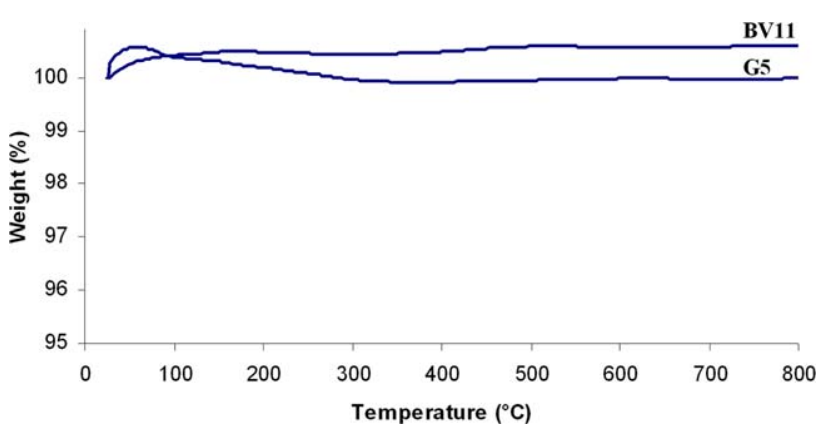

FIGURE 6. TGA of BV11 and G5 samples without silane treatment. [Color figure can be viewed in the online issue, which is available at wileyonlinelibrary.com.]

acrylic bone cement loaded with the calcium phosphate glass containing $\mathrm{Ti}^{4+}$ ions. The FTIR spectra of the biomimetic coatings formed on bone cements with 30 wt \% of BV11sil after 4 weeks in SBF is presented in Figure 10. A sharp vibration band derived from hydroxyl ions is clearly observed at $3550 \mathrm{~cm}^{-1}$ as a shoulder of the abroad absorption band at $3300 \mathrm{~cm}^{-1}$ originated from $\mathrm{H}_{2} \mathrm{O}$. The bending mode band at $1650 \mathrm{~cm}^{-1}$ from $\mathrm{H}_{2} \mathrm{O}$ was also observed in the spectrum as usual for precipitated coatings. ${ }^{24}$ A broad phosphate band derived from the P-O asymmetric stretching mode $\left(v_{3}\right)$ of the $\left(\mathrm{PO}_{4}\right)^{3-}$ group was found in the region from 1200 to $1100 \mathrm{~cm}^{-1}$ and the other small bands at 1031 and 1004 $\mathrm{cm}^{-1}$ are also associated with $v_{3} \mathrm{PO}_{4}{ }^{3-25}$ The bands at 1460 $\mathrm{cm}^{-1}, 1420 \mathrm{~cm}^{-1}$, and $875 \mathrm{~cm}^{-1}$ typical of the $\mathrm{CO}_{3}{ }^{2-}$ group of carbonated apatite were difficult to assign indicating that the content of $\mathrm{CO}_{3}{ }^{2-}$ is low. ${ }^{24}$ However, the characteristic peaks at $927 \mathrm{~cm}^{-1}$ could indicate the presence of $\mathrm{HPO}_{4}{ }^{2-}$ in the crystal lattice. ${ }^{24}$ The band at $752 \mathrm{~cm}^{-1}$ could be associated with particles of BV11sil which were removed from the surface. The results indicate that the $\mathrm{Ca} / \mathrm{P}$ deposit is most likely formed by an apatite with low content of carbonate; the presence of $\mathrm{HPO}_{4}{ }^{2-}$ could indicate a deficiency of calcium in the newly formed coating.

\section{DISCUSSION}

The aim of this work was to study in depth the silanation process of calcium phosphate glasses and to examine the effect of the addition of treated glasses on the bioactive behavior of glass-PMMA composites. Calcium phosphate glasses are materials with good perspective to develop bio-

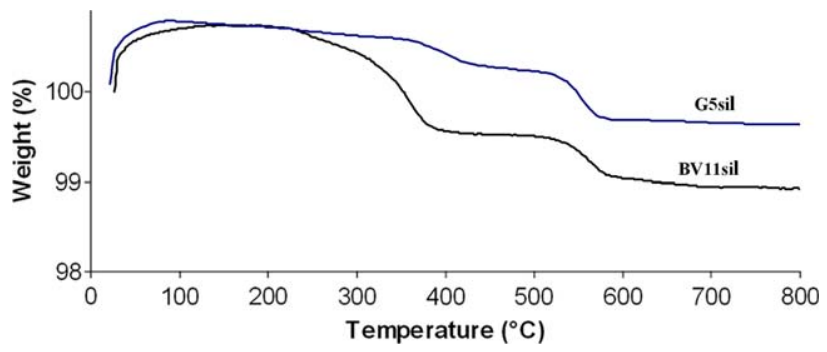

FIGURE 7. TGA of BV11sil and G5sil samples. [Color figure can be viewed in the online issue, which is available at wileyonlinelibrary. com.]

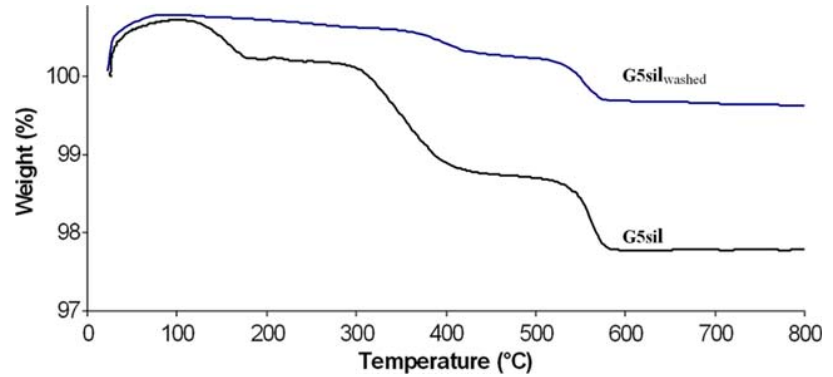

FIGURE 8. TGA of G5sil and G5sil exhaustively three times washed with acetone. [Color figure can be viewed in the online issue, which is available at wileyonlinelibrary.com.]

degradable materials for medical applications because of their solubility. The interest on this type of glasses is owing to their similarity with the chemical composition of natural bone, then, good biocompatibility and low toxicity are expected. The solubility of calcium phosphate glasses can be personalized according to its specific application by modifying its composition. Calcium phosphate glasses in combination with different polymers allow the development of biodegradable or biostable composites with load-bearing requirements.

In this work, two types of calcium phosphate glasses were chemically modified by anchoring a silane coupling agent to its surface. The $\gamma$-MPS condenses with the inorganic particles as the methacrylic group is able to polymerize with the organic matrix. The use of silane coupling facilitates the incorporation of the filler to the cement mixtures since a homogeneous dough paste is obtained. The addition of fillers chemically linked to the composite matrixes favours their mechanical properties and in the case of calcium phosphate glasses the presence of Si ions may contribute to the bioactive performance of the composite.

\section{Glass powder characterization}

The characterization by microprobe chemical analysis of the synthesized glasses revealed slight differences between the nominal and the actual composition of the samples. In the literature these variations are attributed to the fact that glasses containing around 50 wt $\%$ of $\mathrm{P}_{2} \mathrm{O}_{5}$ (methaphosphate glasses) are very difficult to obtain preserving its exact chemical composition. ${ }^{26}$ The presence of the functional groups from the silane agent in the FTIR spectra for both silanated glasses corroborates the efficiency of the silanation process. XPS characterization enabled the identification of the major surface components on untreated and

TABLE III. Thermal Parameters Measured of Unsilanated Glasses and Silanated Glasses

\begin{tabular}{lcccc}
\hline Sample & $T_{\mathrm{g}}\left({ }^{\circ} \mathrm{C}\right)$ & $T_{\mathrm{c} 1}\left({ }^{\circ} \mathrm{C}\right)$ & $T_{\mathrm{c} 2}\left({ }^{\circ} \mathrm{C}\right)$ & $T_{\mathrm{m}}\left({ }^{\circ} \mathrm{C}\right)$ \\
\hline BV11 & 383 & 513.7 & 568.7 & 743.7 \\
BV11sil & - & 513.2 & 583.2 & 745.1 \\
G5 & 506 & 681.8 & 701.8 & 761.8 \\
G5sil & - & 702.5 & 744.7 & $>800$ \\
\hline
\end{tabular}


a)
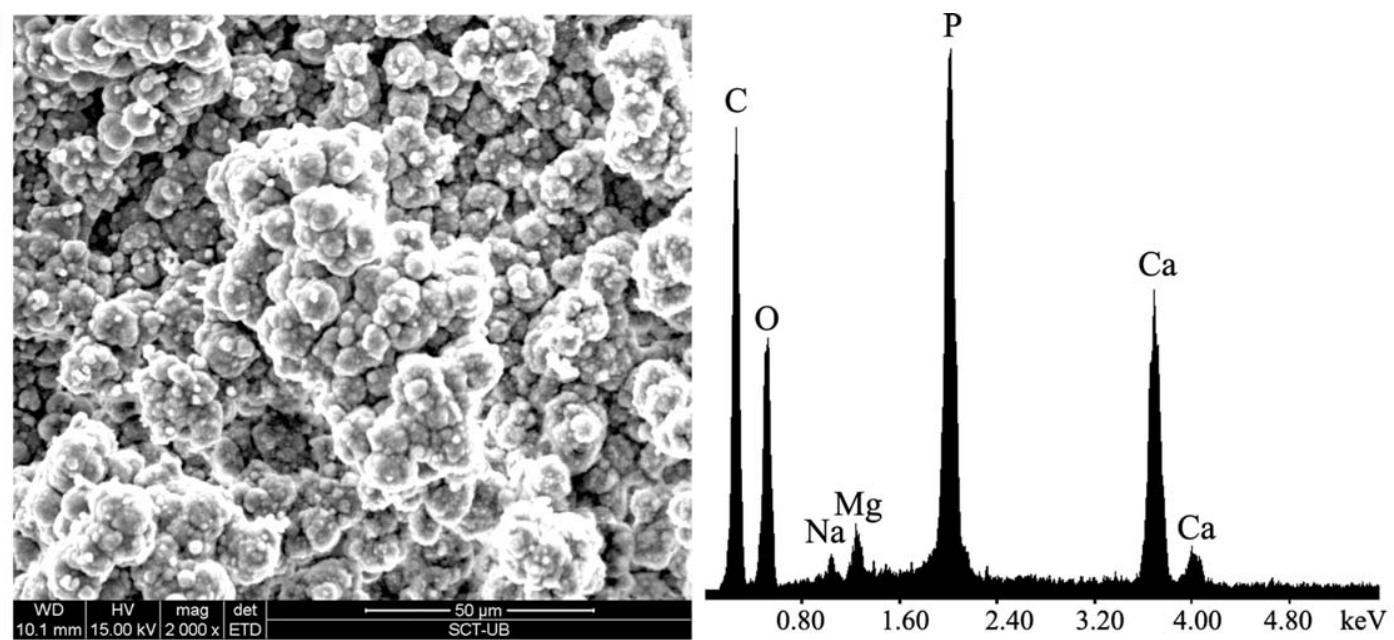

b)
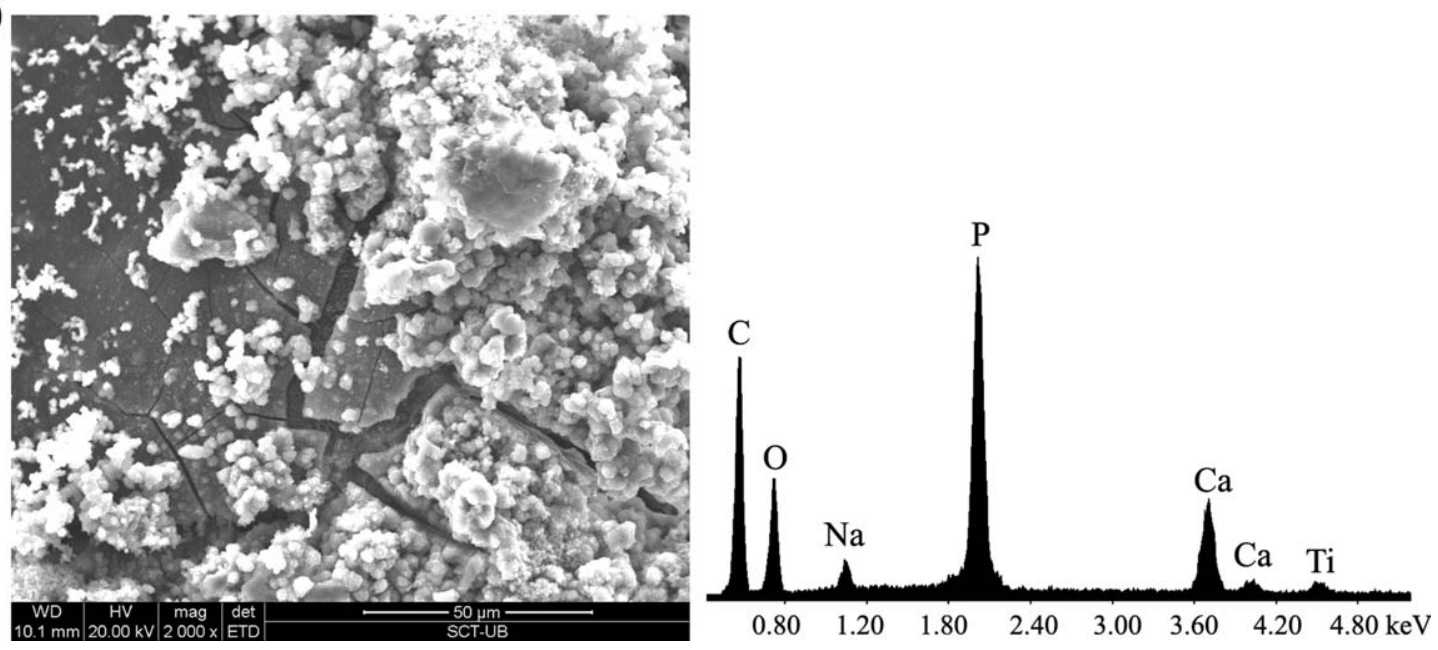

FIGURE 9. SEM micrographs and EDX spectra of glass-PMMA composites after 30 days of soaking in SBF. (a) PMMA-30 wt \% of BV11sil; (b) PMMA-30 wt \% of G5sil.

treated glasses. In addition, XPS results confirm the establishment of chemical bonds between the silane coupling agent and the substrates and not only physical adsorption. The decrease of Ca (2p) and $\mathrm{P}(2 \mathrm{p})$ peaks demonstrates the chemical linkage between the coupling agent and the glasses. As mentioned before, the efficiency of the
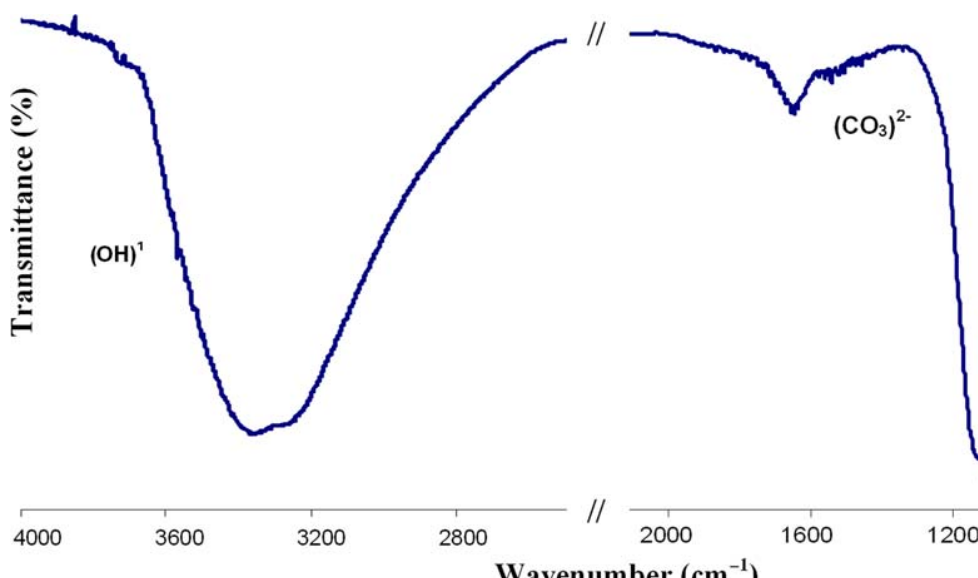

1600

Wavenumber $\left(\mathrm{cm}^{-1}\right)$

FIGURE 10. FTIR spectrum of the biomimetic coatings formed on bone cements with $30 \mathrm{wt} \%$ of BV11sil after 30 days of soaking in SBF. [Color figure can be viewed in the online issue, which is available at wileyonlinelibrary.com.] 
silanation process made easier the mixing process of the fillers with PMMA cement, also is positive to the mechanical behavior of modified composites as a consequence of the formation of a siloxane bond between the filler and the coupling agent in addition to the covalent binding to the resin matrix. ${ }^{27}$ Hydrophobic polymers such as PMMA do not usually adhere to glass and for this reason cracks may grow under load through the microvoids of the interface and breakdown the final material at low stresses. The use of a coupling agent is very common to make compatible inorganic fillers and matrixes but few works demonstrated the efficiency of this reaction prior to their use.

Thermal analysis revealed differences in the two systems of glasses studied. The glass transition temperature $\left(T_{\mathrm{g}}\right)$ of G5 glass was higher than $T_{\mathrm{g}}$ of BV11 glass corresponding to the presence of $\mathrm{TiO}_{2} . \mathrm{Ti}^{4+}$ ion occupies interstitial positions in the glass structure and has the ability to form cross-linking, which not only increases the temperature of the thermal transformations ${ }^{13,15}$ but also increases modulus, hardness and aqueous stability. Thermal analysis confirms the occurrence of two $T_{\mathrm{c}}$ peaks which are indicative of the existence of two crystalline phases present in the particular compositions prepared. The silanation process doesn't have a clear effect in the thermal transformations of the glasses. In the G5sil sample a slight increase in $T_{\mathrm{c} 1}$ and $T_{\mathrm{c} 2}$ occurred, but for the BV11sil sample this effect was not detectable.

Through the thermogravimetric study it was possible to quantify the bounded silane agent content of treated glasses. No change was detected for untreated glasses for all temperature range $\left(25-800^{\circ} \mathrm{C}\right)$, Figure 6; however, for treated glasses two or three weight losses were clearly detected, Figures 7 and 8 . When the glasses are washed using a conventional technique some adsorbed silane coupling agents persist on the sample, while for extremely washed silanated glasses, only the linkage silane agent was detected. In this case two-step weight losses were observed, the first weight-loss step indicated only tightly bound silane remained on the surface of the glass and the second weightloss step is associated to condensation of surface silanols. Despite of slight differences in BET surface area for both untreated glass particles, BV11sil resulted got twice the amount of silane coating (1.69 $\pm 0.02 \mathrm{wt} \%)$ in comparison with G5sil glass (0.93 \pm 0.01 wt $\%)$, which may be explained because the BV11 glass is more sensitive to the erosion process.

\section{Bioactivity behavior of Glass-PMMA composites}

PMMA, the main component of conventional acrylic bone cements, is not a bioactive material. On the contrary longterm clinical evidence confirms the growth of a fibrous membrane around the cement, which partially isolates the implant and weakens the cement-bone interconnection. ${ }^{28}$ The use of bioactive inorganic fillers to evolve bioactive composites nowadays is a common route to obtain new materials. In this work, some glass-PMMA composites were prepared using calcium phosphate glasses with different aqueous stability to develop partially biodegradable cements. In the preparation of composites from acrylic cement the major content of filler is occluded by the matrix as a consequence of the setting process. Only a low percent of the filler remains at the material surface and it may be erosionable by body fluids depending of their solubility. However, theoretically if the filler has enough bioactive performance new bone may growth to fill the free surface space as well as to establish a direct linkage with the bioactive cement assuring the interfacial strengths.

Several works related with calcium phosphate glasses discuss their potential uses as biomaterials. ${ }^{13,28}$ The dissolution behavior in the living body of calcium phosphate glasses around the metaphosphate composition is highly valuable to develop three dimensional structures intended for tissue engineering scaffolds, ${ }^{3,7,8,13,23}$ but there are almost no clearly reports on their bioactivity. ${ }^{28}$ Some authors explored the preparation of bioactive calcium phosphate glasses in the pyrophosphate region and controlled their crystallization to develop bioactive glass-ceramic for biomedical use. ${ }^{28}$ The compositions explored were based on $\mathrm{xCaO}-(90-\mathrm{x}) \mathrm{P}_{2} \mathrm{O}_{5}-10 \mathrm{TiO}_{2}$ in $\mathrm{mol} \%$ and the results showed that bonelike apatite started to form on the surface of $60 \mathrm{CaO}-30 \mathrm{P}_{2} \mathrm{O}_{5}-10 \mathrm{TiO}_{2}$ (in mol\%) after 10 days, nevertheless, no apatite formation occurred on the $55 \mathrm{CaO}-35 \mathrm{P}_{2}$ $\mathrm{O}_{5}-10 \mathrm{TiO}_{2}$ and $50 \mathrm{CaO}-40 \mathrm{P}_{2} \mathrm{O}_{5}-10 \mathrm{TiO}_{2}$ glasses even after 30 days of soaking. ${ }^{28}$

In this work, a preliminary in vitro bioactivity test was carried out employing silanated BV11 and G5 glasses as filler of PMMA cement and formation of calcium phosphate coating on the composite surface was observed. When is used BV11sil after 30 days the layer is formed on the whole surface, and in the case of use of G5sil filler the deposit is on some areas of the surface. The higher solubility of the BV11 calcium phosphate glass increases the interchange of ions with the environment since the initial stages of the immersion in the SBF solution, enhancing the nucleation and precipitation of calcium phosphate compounds. As previously mentioned, the FTIR gives qualitative evidence that the calcium phosphate formed on the composite surface could be apatite-like layer with a low content of $\mathrm{CO}_{3}{ }^{2-}$ and certain amount of $\mathrm{HPO}_{4}{ }^{2-}$ in its structure. The FTIR spectrum of coating obtained was similar to those formed in $\mathrm{SBF}$ in other recognized bioactive materials. ${ }^{24}$ Further studies are required to confirm the chemical and crystallographic composition of the calcium phosphate coating. Experiments on PMMA with non silanated BV11 and G5 glasses as fillers did not reveal bioactive performance at 30 days after soaking. So, taking into account that the conventional acrylic cement is not a bioactive material, the addition of 30 wt \% of any silanated calcium phosphate glass used in this work would be an appropriated way to achieve a bioactive composites considering the results of this in vitro study.

\section{CONCLUSIONS}

In this work, two type of calcium phosphate glasses with different solubility were synthesized. The efficiency of the 
silanation reaction was verified qualitatively and quantitatively by different analytical techniques. It was demonstrated that chemical linkage exists between the coupling agent and treated glasses, where the content of bound silane ascends to $1.69 \pm 0.02 \mathrm{wt} \%$ for $44.5 \mathrm{CaO}-44.5 \mathrm{P}_{2} \mathrm{O}_{5}$ $11 \mathrm{Na}_{2} \mathrm{O}$ (BV11sil) glass and $0.93 \pm 0.01$ wt $\%$ for $44.5 \mathrm{CaO}-$ $44.5 \mathrm{P}_{2} \mathrm{O}_{5}-6 \mathrm{Na}_{2} \mathrm{O}-5 \mathrm{TiO}_{2}$ (G5sil) glass. The silanation process was found to be decisive to the bioactive behavior of $30 \mathrm{wt}$ $\%$ glass-PMMA composites in the in vitro SBF test. The formation of a $\mathrm{Ca} / \mathrm{P}$ rich layer was more intensive on the materials filled with BV11sil than for composites with G5sil glass particles for the period of study.

\section{ACKNOWLEDGEMENTS}

The authors acknowledge the financial support provided to José Angel Delgado by a grant Erasmus Mundus (ÁnimoChévere) for its contribution to obtaining the results of this work. We also thank to Scientific and Technological Centre of Barcelona University for analytical data acquisition.

\section{REFERENCES}

1. Wilson J, Yli-Urpo A, Happonen R-P. Bioactive glasses: Clinical applications. Hench LL, WJ, editors. ed. An Introduction to Bioceramics. Singapore: World Scientific; 1993. pp 63-73.

2. Hench L. The story of bioglass. J Mater Sci Mater Med 2006;17: 967-978.

3. Fu Q, Saiz E, Rahaman MN, Tomsia AP. Bioactive glass scaffolds for bone tissue engineering: State of the art and future perspectives. Mater Sci Eng C 2011;31:1245-1256.

4. Jones JR. Review of bioactive glass: From Hench to hybrids. Acta Biomaterialia 2013;9:4457-4486.

5. Vogel W, Holand W. Development, structure, properties and applications of glass-ceramic for medicine. J Non-Cryst Solids 1990; 123:349-353.

6. Kokubo T, Takadama $\mathrm{H}$. How useful is SBF in predicting in vivo bone bioactivity? Biomaterials 2006;27:2907-2915.

7. Ahmed I, Lewis M, Olsen I, Knowles JC. Phosphate glasses for tissue engineering, Part 1. Processing and characterisation of a ternary-based P2O5-CaO-Na2O glass system. Biomaterials 2004; 25:491-499.

8. Ahmed I, Lewis M, Olsen I, Knowles JC. Phosphate glasses for tissue engineering, Part 2. Processing and characterisation of ternary-based P2O5-CaO-Na2O. Biomaterials 2004;25:501-507.

9. Navarro M, Ginebra MP, Planell JA. Cellular response to calcium phosphate glasses with controlled solubility. J Biomed Mater Res Part A 2003:67:1009-1015.

10. Bitar M, Salih V, Mudera V, Knowles JC, Lewis MP. Soluble phosphate glasses: In vitro studies using human cells of hard and soft tissue origin. Biomaterials 2004;25(12):2283-2292.

11. Franks K, Salih V, Knowles JC, Olsen I. The effect of MgO on the solubility behaviour and cell proliferation in a quaternary soluble phosphate based glass system. J Mater Sci Mater Med 2002;13: 549-556.
12. Franks K, Abrahams I, Knowles JC. Development of soluble glasses for biomedical use. I. In vitro solubility measurement. J Mater Sci Mater Med 2000;11:609-614.

13. Navarro M, Del Valle S, Ginebra MP, Martínez S, Planell JA. Development of new calcium phosphate glass ceramic porous scafffold for guided bone regeneration. Key Eng Mater 2004;254256:945-948.

14. Navarro M, Ginebra MP, Clément J, Martínez S, Ávila G, Planell JA. Physicochemical degradation of titania-stabilized soluble phosphate glasses for Medical applications. J Am Ceram Soc 2003;86:1345-1352.

15. Simon V, Muresan D, Simon S. Iron effect on glass stability of sodium-calcium-phosphate glasses. Eur Phys J Appl Phys 2007; 37:219-222.

16. Lopes $\mathrm{P}$, Corbellini $\mathrm{M}$, Ferreira $\mathrm{BL}$, Almeida $\mathrm{N}$, Fredel $\mathrm{M}$, Fernandes ME, Correia R. New PMMA-co-EHA glass-filled composites for biomedical applications: Mechanical properties and bioactivity. Acta Biomaterialia 2009;5:356-362.

17. Georgiou G, Mathieu L, Pioletti DP, Bourban P-E, Månson J-AE, Knowles JC, Nazhat SN. Polylactic acid-phosphate glass composite foams as scaffolds. J Biomed Mater Res Part B:Appl Biomater 2007:80:322-331.

18. Shinzato $S$, Kobayashi $M$, Mousa WF, Kamimura M, Neo M, Kitamura $\mathrm{Y}$, Kokubo T, Nakamura T. Bioactive polymethylmethacrylate-based bone cement: Comparison of glass beads, apatiteand wollastonite-containing glass-ceramic, and hydroxyapatite fillers on mechanical and biological properties. J Biomed Mater Res 2000;51:258-272.

19. Liu Q, Ding J, Chambers DE, Debnath S, Wunder SL, Baran GR. Filler-coupling agent matrix interactions in silica/polymethylmethacrylate composites. J Biomed Mater Res 2001;57:384-393.

20. Uo M, Mizuno M, Kuboki Y, Makishima A, Watari F. Properties and cytotoxicity of water soluble Na2O-CaO-P2O5 glasses. Biomaterials 1998;19:2277-2284.

21. Clément J, Manero JM, Planell JA, Ávila G, Martínez S. Analysis of structural changes of a phosphate glass during its dissolution in simulated body fluid. J Mater Sci Mater Med 1999;10:729-732.

22. Lee YK, Choi SH. Novel calcium phosphate glass for hard-tissue regeneration. J Korean Acad Periodontol 2008;38:273-298.

23. Navarro M. Desarrollo y caracterización de materiales biodegradables para regeneración ósea. PhD Thesis, Universitat Politècnica de Catalunya, Spain; 2005.

24. Müller L, Müller FA. Preparation of SBF with different $\mathrm{HCO}_{3}{ }^{-}$content and its influence on the composition of biomimetic apatites. Acta Biomater 2006;2:181-189.

25. Eichert D, Drouet C, Shifia H, Rey C, Combes C. Characterization of Apatites. Nanocrystalline Apatite-Based Biomaterials. New York: Nova Science Publishers; 2009. pp 13-27.

26. Morejón L, Mendizabal E, García-Menocal JA, Ginebra MP, Aparicio C, Mur FJ, Marsal M, Davidenko N, Ballesteros ME, Planell JA. Static mechanical properties of hydroxyapatite (HA) powder-filled acrylic bone cements: Effect of type of HA powder. J Biomed Mater Res B Appl Biomater 2005;72:345-52.

27. Charnley J. The reaction of bone to self-curing acrylic cement. A long-term histological study in man. J Bone Joint Surg 1970;52 Br:340-353.

28. Kasuga T. Bioactive calcium pyrophosphate glasses and glassceramics. Acta Biomaterialia 2005;1:55-64. 